\title{
Designing the Teaching Process in a Modern Educational Institution
}

\author{
Bialyk O. ${ }^{1}$, Demchenko I. ${ }^{2, *}$, Pryshchepa S. ${ }^{1}$, Dushechkina N. ${ }^{3}$ \\ ${ }^{1}$ Department of Pedagogy and Educational Management, Pavlo Tychyna Uman State Pedagogical University, 20301, Ukraine \\ ${ }^{2}$ Department of Special Education, Pavlo Tychyna Uman State Pedagogical University, 20301, Ukraine \\ ${ }^{3}$ Department of Chemistry, Ecology and Their Teaching Methods, Pavlo Tychyna Uman State Pedagogical University, 20300, Ukraine
}

Received November 11, 2020; Revised December 8, 2020; Accepted December 20, 2020

\section{Cite This Paper in the following Citation Styles}

(a): [1] Bialyk O., Demchenko I., Pryshchepa S., Dushechkina N., "Designing the Teaching Process in a Modern Educational Institution," Universal Journal of Educational Research, Vol. 8, No. 12A, pp. 7723 - 7732, 2020. DOI: 10.13189/ujer.2020.082559.

(b): Bialyk O., Demchenko I., Pryshchepa S., Dushechkina N. (2020). Designing the Teaching Process in a Modern Educational Institution. Universal Journal of Educational Research, 8(12A), 7723 - 7732. DOI: 10.13189/ujer.2020.082559.

Copyright $\mathrm{C} 2020$ by authors, all rights reserved. Authors agree that this article remains permanently open access under the terms of the Creative Commons Attribution License 4.0 International License

\begin{abstract}
This paper focuses on the instructional design, its functions, approaches and principles. Instructional design plays a significant role in ensuring coherent, relevant and effective educational process and must be considered in more depth by modern teachers and educators. Today, without radical changes in educational trends, the process of personal development will continue to be monotonous and impoverished. Authors suggest, that nowadays special attention should be paid to the educational function of the school, aimed at developing a person because the assimilation of knowledge by students must pass through a pre-determined system of educational work. It is important to broadly involve students in planning the process, as well as in the actual implementation of creative ideas. The type of communication within the class group, the student's progress, behaviour within the school and outside it will largely depend on the nature of the activities of students. An important element of work in this area is the involvement of schoolchildren's families, active cooperation with them, the realization of a common goal, mutual understanding. To design the work plan of the class group in relation to specific educational objectives and tasks of personal development of students means to create at the level of personal development of students the most optimal system of activities, where methods and organization will be oriented towards the development of all subjects of interaction.
\end{abstract}

Keywords Instructional Design, Teaching, Modern Education, Pedagogics, Student's Youth

\section{Introduction}

The processes of society democratization, the awakening of national consciousness, taking an individual approach to the individual's education is designed to change the educational activities with student's youth completely. State policy in the field of education is determined by the principles of humanistic pedagogy, formulated in the Laws of Ukraine "On education", "On General Secondary Education", the National Program of Education, the United Nations Convention on the Rights of the Child. The development of Ukraine puts forward such important and crucial task as education of the new generation that is capable not only to comprehend the essence of person's existence but also to address it creatively according to requirements of the time [1].

The new system of education in Ukraine is introduced against the controversial and difficult situation, which is presented as economic instability and spiritual decay of society. Modern problems cause new difficulties in the education of students. The aggravation of the educational situation is greatly influenced by the activities of the school, which embodies significant changes in education, 
but has not yet been able to get rid of the monotony of educational activities, the attitude towards students as towards an object of education. Currently, there is a standardization of educational activities, the lack of a coherent system of education, monological approach in communication between teachers and students, the priority is the direct impact on the student and not the self-development of the student's personality. This situation is critical because the State has set a task for teachers to develop a person who inherently possesses the universal values, proactive attitude and similar qualities [2].

Despite the above-stated, the educational process in the modern educational institution consists mainly of the so-called public assignments, incentives and penalties. The idea that the true essence of educational work is not in conversations with the students, but in the direct impact on them, in the organization of the students' life, remains presently important [3].

Experience in the management of the educational process in general education institutions indicates the need for the development of a specific level in management practice - the level of design of scientific and psychological knowledge on the real problems existing in modern educational institutions [4]. The main purpose of planning in the context of the new educational paradigm is not only to ensure the functioning of educational establishments when available management capabilities are used within the framework of the corresponding requirements but also their development as a quality increase in new features and their implementation [5].

According to [6], the openness of society to different systems of values makes the problem of teaching a person to be capable of conscious value choice very relevant. In this regard, it is necessary to search for new approaches to education and training, allowing to create an environment where the content, filled with universal values, will contribute to the formation of a moral personality. It is important to provide competent pedagogical support for intellectually capable students at the stage of their education at school. In this case, the special attention of teachers should be given to the formation of students' socially significant values [7].

The system of value orientations expresses a person's attitude to the world and to himself/herself in the form of fixed sets on certain values of material and spiritual culture of society, thereby having a significant impact on own behaviour and activities [8].

Since the instructional design is based on the importance of the course content, style and sequence of presentation of the material, it builds a unified system of learning objectives, educational material and tools available for the knowledge transfer [6].

The basis of the formation and development of value orientations of personality comprises several conditional stages: 1) the assimilation of value knowledge; 2) the actuation of feelings, that is, the emotional perception of the acquired knowledge; 3) their manifestation in behaviour and various activities. In this regard, the process of formation of value orientations can be more effective if familiarization with them occurs using the means of instructional design [6].

It is important to incorporate the goal of developing moral and value orientation in students on the preliminary stage of the educational process, which should be the instructional design. Instructional (teaching) design is an activity that is carried out in the conditions of the educational process, aimed at ensuring its effective functioning and development. It is necessitated by the need to solve the existing pedagogical problem and has a creative character [9].

Merrill et al. in their book [10] interpret instructional design as a technology for the development of learning experiences and environments which foster the acquisition of certain knowledge and skills by students. The instructional design incorporates known and verified learning strategies into teaching experiences which make the acquisition of knowledge and skills more efficient.

According to [11], instruction or teaching is a systematic process, in which every component (teacher, learners, materials, and learning environment) plays a significant role in successful learning. The systematic approach to the instructional design consists of such stages, as planning, development, implementation, and evaluation of instruction.

According to [12], instructional design requires numerous interrelated and interdependent factors to be considered. The goals and objectives of the educational process must be specified in the first place since all the next steps will rely on them. İşman states that during the process of steps determination, the following important principles play a significant role: 1 . the planning process must begin from clearly identifying goals and objectives students are expected to attain; 2 . further instructional activities must help students to achieve those objectives; 3 . assessment instruments measuring the level of achievement must be developed; 4. Instruction must be revised according to student performance on each objective and student attitudes towards instructional activities [13].

The authors of [14] suggest that the immediate and long-range phases of teaching planning are best performed as separate tasks and not mixed together. According to the authors, to design instruction, one must seek a means of identifying the human capabilities that lead to the outcomes called educational goals. However, instruction cannot be adequately planned separately for each educational goal important to modern society. One must seek, instead, to identify the human capabilities that contribute to a number of different goals. There is a growing sociocultural importance of a teacher as a creator of a social context of the education development and its 
systemic interaction with society $[15,16]$.

A typical model of instructional design has an abbreviated name ADDIE and consists of 5 interdependent long-repeated phases:

1) Analysis, which is a preliminary analysis of the goals and objectives of learning, understanding the level and profile of students, thinking through the necessary steps to advance to the goal;

2) Design, which is setting goals and objectives of learning, choosing the format of the course and classes, creating a learning strategy;

3) Development of course materials, methodology and techniques of their presentation in the educational process;

4) Implementation of the developed course materials;

5) Evaluation of learning outcomes, mainly, the level of proficiency in the subject of students. This stage usually takes place at the end of the ADDIE model, but is appropriate at all stages, because the evaluation should be conducted on an ongoing basis, which helps to review the entire learning process and make adjustments in time.[17]

The study of [10] suggests that there are several characteristics that should be present in all instructional design efforts: 1. Instructional design is student-centred. 2. Instructional design is goal-oriented. 3. Instructional design focuses on meaningful performance. 4. Instructional design assumes outcomes can be measured in a reliable and valid way. 5. Instructional design is empirical, iterative, and self-correcting. 6. Instructional design typically is a team effort.

\section{Materials and Methods}

The main goal of the present study is to substantiate the theoretical and methodical principles of teaching design in modern educational institutions. The tasks that are needed for achieving the set goal are the investigation of principles of teaching (instructional) design of the educational activities, defining its role in the whole educational process, the study of the existing research works on the stated problem in order to compare the different opinions of the researchers from the relevant field. During the study, the authors conducted the analysis of academic and theoretical sources in the field of education, as well as Program "Conceptual framework of basic guiding principles of education of 1-12-grades students of general educational institutions of Ukraine" [18] to get more insight into the present state of the problem and used the following methods for achieving the goal put forward: theoretical, such as retrospective and comparative analysis of philosophical, sociological, psychological and pedagogical literature on the studied problem; analysis, synthesis, generalization, classification of theories, facts; empirical methods; prognostic methods (expert assessments, the generalization of independent characteristics).

All students - 642 people - were divided into three groups: two control (CG1, CG2) and nonexperimental (EG). In the first control group - 210 persons (CG1) training was carried out according to traditional approaches, that is, training was conducted in lecture rooms and computer classes of higher educational establishments. Since not all students had the opportunity to work on computers and use gadgets, they were given an additional opportunity to work in computer classes. Students of the second control group -215 persons (CG2) - underwent an on-line form of training with the elements of distance one, the essence of which was the presentation of educational information in electronic form. Students had the opportunity to work in a developed design of cloud-oriented environment at any time.

To a certain extent, the CG control group is also an experimental group when comparing groups CG1 and CG2, but the research logic requires that it should be included in the control one since it was more important for us to compare it with the experimental group, where the developed system of teacher training system was fully utilized in the informational environment - the educational environment of the university, which envisioned the use of all systematic opportunities provided by the cloud-oriented environment, namely: the availability of teaching and methodical complex (TMC) $24 / 7$, regardless of the location of the subjects of the education process; managing the education process in the same mode; availability of teacher's recommendations and instructions off-line; ability to create personal cloud storage of training materials and e-portfolio management.

The third group-the experimental group- 217 people (EG); pedagogical training of students entering it took place under the author's system in the conditions of the informational and educational environment of the university. During the formation of these groups, the lack of significant differences in the level of previous knowledge and skills formation was checked. In the general group I, the group CG1 included 107 students, the second control group CG2 - 103 people. The experimental group (EG) included 111 people.

Students of the general group II were divided in the same way into three groups: two control $(\mathrm{CG} 1, \mathrm{CG} 2)$ and one experimental (EG). Thus, the group CG1 included 98 students, the second control group CG2 - 117 students and the experimental group - 106 students. To exclude the subjective influence of the experimenter and to create the same conditions for all participants of the experiment, the following measures were proposed and used: all experimental activities were carried out by teachers who received clear instructions on the procedure and conditions for conducting the experiment; students who participated in the experiment also received single clear instructions; the use of computer technology was 
organized in such a way as to disable the teacher's influence on the course of the experiment, and with the help of the calculation automation to objectively evaluate the results of the experiment.

In accordance with the goals, the following methods were used at various stages of the research: theoretical methods: retrospection, comparison, logical analysis of philosophical, psycholopedagogical and methodical sources, dissertations - to specify the condition and prospects of the research problem; synthesis, generalization, theoretical design - to reveal the essence of the problem, to outline the basic concept and terminology, to justify a structural and functional model of experimental training, to distinguish the main components of future teachers' professional training to implement educational technologies in physical education, to characterize technological competency in the general structure of professional competency; empirical methods: diagnostic methods (psycho-pedagogical observation, conversations, testing, questionnaires, interviews); pedagogical experiment with qualitative and quantitative analysis of results, their statistical processing; personal pedagogical scientific and practical experience, which made it possible to introduce a system of training future physical education teachers to implement educational technologies into the real education process in higher education institutions and verify its effectiveness at various educational and qualification levels.[19]

\section{Results and Discussion}

The vast majority of teachers do not pay attention to the individual characteristics of students; they implement educational activities without analyzing the potential outcome. Under such conditions, there is no time for spiritual communication between teachers and students, and therefore, the possibility of pedagogical influence on the physical, intellectual, social and spiritual spheres of students' life, on the formation of necessary qualities and characteristics of personality is narrowed down. In the educational institution, educational work is carried out by means of a prescriptive approach, which can be outlined according to the scheme "demand - perception-action". There is little understanding between teacher and student: teacher and student are too far apart. The educational process, which is continuously built on submission, the humiliation of the children, does not promote their spiritual and social development.[20]

Researcher [21] notes that, first of all, it is necessary to overcome the system of detachment: schools from society; administrative bodies from the school; teaching staff from students; students from the school and teachers. There are some positive shifts, but they are almost imperceptible.

At the moment, only some schools select new forms of organization of life and activities of students, revive or create new youth and children's public associations and find optimal educational systems of interaction with children. Teachers and educators are increasingly inclined to the idea that education, as the development of personality, is not a mandatory and autonomous process of the school and automatically decline responsibility for the development of personal qualities and characteristics of the students during the period of study at school, and, consequently, for the development of personality.[22]

Today, the opinion of A. Makarenko is gaining the current importance, and he noted that there is virtually no development of students in an educational institution, nothing is required of them, except primitive brakes, necessary for our convenience, so that they would sit quietly in the classroom. Sometimes in the actions of teachers, there is still a discipline of the order, but there is no discipline of struggle and overcoming. Teachers wait until the students take a certain misstep, and then begin to "educate" them. The student who does not make mistakes does not provoke interest in what character develops in his/her apparent external order.

Another important opinion of [23] is that in the pedagogical theory it is necessary to rely on the mutual purposeful interaction of the teacher and students, as the main attention in practice focuses on the activity of the teacher. The teacher acts as the subject of the educational process, and the student - as an object. The educational process is carried out without a specific addressee, user, customer, and involves everyone and intended for everybody. It does not ensure the unity of all links of the system of continuous education and person development, continuity in determining goals, objectives, activities. It is aimed primarily at the mental development of the individual, which constitutes a certain amount of knowledge, skills and abilities. At the same time, the process of harmonious personal development of an individual, his/her physical, intellectual, social and spiritual development remain spontaneous and unregulated. There are two ways of socialization: spontaneous and regulated, which should be in harmony, and in most cases, the first, that is, spontaneous, is more often used in practice (Kirichuk 2009).

Indeed, without radical changes in educational trends, the process of personal development will continue to be monotonous and impoverished. Today, the problem of the educational process organization has become particularly acute due to a number of circumstances. The first of them is connected with the comprehension of the highest value, which is a person and his/her life. Another one is caused by the fact that the modern generation lives on the cusp of epochs, which is due to the rejection of outdated forms of life and the formation of new civilizational foundations of life.

In our opinion, today, we should pay special attention to the educational function of the school because of the assimilation of knowledge by students must pass through 
a pre-determined system of educational work. Even when education is quite favourable and functions in socially accepted forms, it should be supplemented by thoughtful, creative, purposeful person-developing activities that will expand and enrich the content of the development of an individual, the student's group, which is possible only if designed beforehand.

It can be argued that the analysis of the complex modern educational situation proves the need for a purposeful approach to the educational strategy, which is possible only when there is a well-thought-out design of the educational process in the case of the classroom and school-wide groups.

Changing the principles of education, their orientation to the life-active person, guided by universal and national-cultural values, needs to ensure the unity of theory and practice. Such a link, which combines theory and practice, is the design of the educational process.

The importance of ensuring the educational process design was emphasized by A. Makarenko: "Design is a necessary initial step in the organization of the educational process. As it is impossible to build a house without a project, so it is impossible to develop the right people without having an idea of what qualities should be inherent in them. Only through design can educational goals be included in the organization of the objective process of raising children". [24] The same opinion was held by V. Sukhomlynsky, who stressed that "design and creating a person who can become an active, creative force of social development today and in the future - is the most the important task of school and each teacher in particular" [25]

Thus, instructional design is considered as a result of activity, that is, development of the plan of study of the prospects, creation of a certain image of interaction with students or as the description of the process of transformation of this image on objective reality. It should be noted that instructional design is a function of any teacher, no less important than organizational, prognostic or communicative. The instructional design should be understood as a purposeful activity aimed to create a project as an innovative model of educational or training system.

Instructional design is an activity carried out in the educational space and is aimed at ensuring the effective functioning of the educational process and ensures its development. Purposeful activity is caused by the need to solve an urgent problem, has a creative nature, and in the educational sphere - value orientations. The result of instructional design is a model of the object of the pedagogical activity, which is characterized by systemic properties; which is based on pedagogical innovations, as it is based on a new way to solve the problem. Instructional design involves possible options for the application.[13]

Pedagogical projects are multifaceted and more responsive than technical ones. In the technical project, it is possible to list and describe all the elements, whereas in the pedagogical project it is very difficult to perform due to a variety of the pedagogical phenomena, individual features of school students as subjects of its implementations [26]

Instructional design is a sequential process of changing new tasks, activities, levels of information order. Since the instructional design is an activity based on the formation of new tasks of the pedagogical process, it is necessary to highlight the main functions of the design. Based on the analysis of psychological and pedagogical literature, the following functions of instructional design are distinguished (Fig. 1).

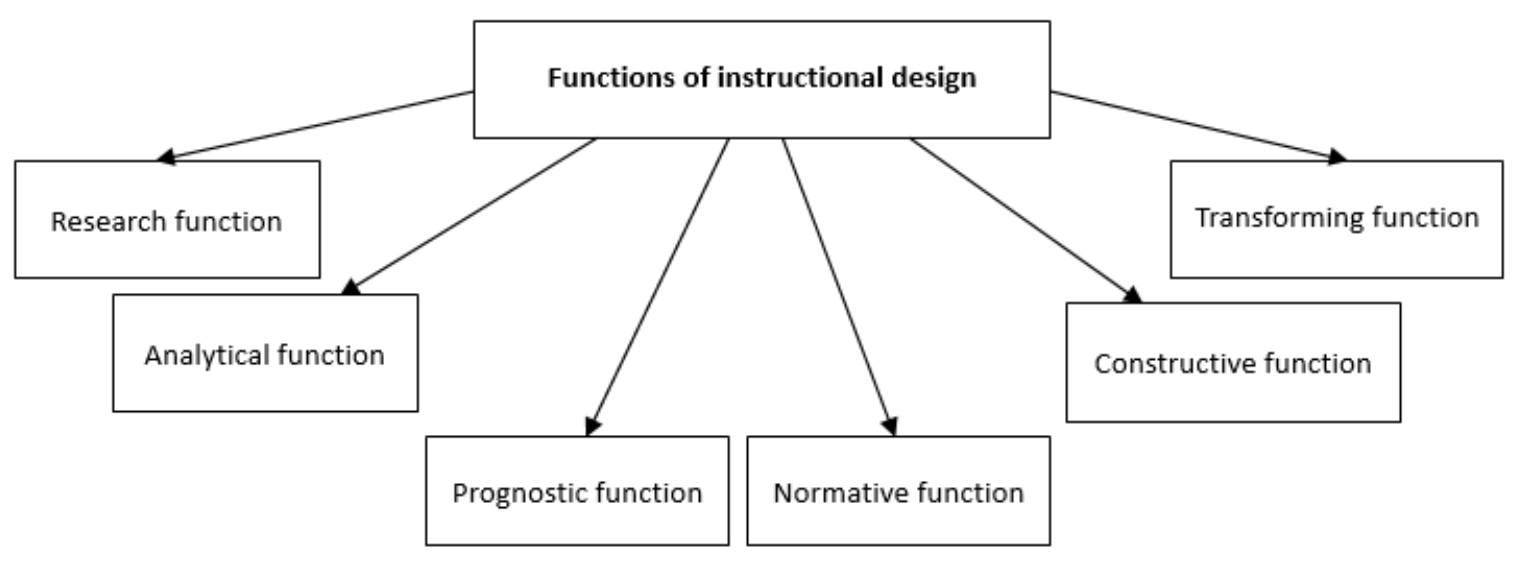

Figure 1. Functions of instructional design 
Now we should consider the principle of each function of the instructional design separately. The research function provides for the study of age and individual characteristics of each student, as well as features of the process and results of project activities, the definition of a number of advantages and disadvantages of the project of educational activities.

The analytical function is associated with the need to analyze the process of education, to compare the results with the goals and objectives. The prognostic function requires the teacher to have necessary skills to predict the development of the personality, his/her qualities, feelings, will; it records possible deviations in the development of the personality, predicts the course of the educational process, considers options for the use of forms, methods and means of education.

Normative function means that design as a process has a normative nature, which is defined by certain stages and forms. The constructive function is associated with the design of the structure of pedagogical actions of the teacher and students. The transforming function contributes to the moral development of the individual, the formation of humanity in interpersonal and intercultural relations.

All of the above functions are interrelated and interdependent; that is, they are all aimed at obtaining a qualitatively new result based on predictive knowledge. Analysis of psychological and pedagogical literature suggests that researchers conditionally distinguish three approaches to the design of the pedagogical process. The functional approach (N. Belokur, S. Kiselgof, N. Kuzmina, K. Levitan, S. Smirnov, M. Tomin, A. Shcherbakov) allows considering the design through the analysis of the content of constructive and design skills.

The approach based on the theory of pedagogical management (Yu. Kuzmina, V. Slastenin, L. Spirin, G. Sukhobskaya) is based on the management activities of the teacher and director. The system approach (V. Bezrukova, S. Vysotskaya, A. Dubaseniuk (1995), V. Kirichuk, A. Kobernyk, V. Kraevsky, A. Ligotsky) justifies the design as an independent pedagogical activity, which provides for the sequence of deployment and implementation of the main components.

According to the American scholar J. Jones, the design process goes through the following stages in its development:

1) divergence (expansion of the boundaries of the design situation in order to provide a sufficiently large space to find a solution to the problem);

2) transformation (creation of principles and concepts);

3) convergence (choosing the best option from a variety of alternatives).

On the basis of studying the features of the pedagogical process, researcher A. Kobernyk highlights specific features of its design:
- the design describes not yet existing objects, that is, the description of the existing pedagogical process can not be considered a project;

- the pedagogical project assumes the unity of the theory and practice of educational process;

- the basis of instructional design is personal-developmental interaction;

- the project can be implemented, that is, the description of the pedagogical process, which can be implemented in practice, is considered as a project;

- the project should be normative, that is, to record the available level of implementation of the relevant actions [27]

Pedagogical design is a continuous process, so each project should be considered as the next key step leading to the creation of the object or subject that fully meets the needs. Thus, the pedagogical design is a stage that precedes the main work and guides for the implementation of pedagogical goals and objectives. It is precisely the means by which it becomes possible to determine the basic guidelines of the teamwork.

A project is a form that determines the efficiency of the pedagogical process and its results, and the design is the main educational activities of the class teacher, as the importance of educational activities design in a modern educational institution is caused by several factors: first, the problem of efficiency of the educational process; second, the necessity of gradual transition to the humanistic paradigm of students education; third, the establishment of a new individual, which is capable of self-determination, self-organization, of self-actualization in the context of modernity.

Since this study examines the design of the educational process of the class group, it is necessary to disclose this concept in greater depth. As a result of the analysis of research works of V. Bezrukova, S. Vysotskaya, A. Dubaseniuk, V. Kirichuk, A. Kirichuk, A. Kobernyk, V. Kraevsky and others, which reveal the essence of the design of the educational process, educational system, etc., it can be concluded that the researchers are not unanimous in the interpretation of the above concepts.

Thus, A. Kobernyk, who is the well-known researcher of the specified problem, considers the design of the educational process as a purposeful creative initial definition and design of the program of joint activity of the subjects of the pedagogical process and its further implementation, aimed at providing a personal-developmental approach to achieving the goal of education.[27]

According to S. Elkanov, the design of educational activities involves the imaginary construction of the final outcome of educational activities and the preparation of a plan of educational actions to achieve the goal and acts as a simulation of the strategic program for achieving educational goals and objectives.[28]

The class teacher is the leading organizer of education 
in school, and thus, in our opinion, it is the class teacher who during pedagogical work needs to pay significant attention to the design system in the education of children.

The most difficult function of the class teacher is educational, contributing to the development of a person. To be an educator means to be able to transform the goals that society has set for the school into specific pedagogical tasks - the formation of the necessary personality qualities in each student.

The main activities of the class teacher are:

- introduction of new pedagogical technology;

- education under the conditions of formation of the national school as an open educational system;

- work with student's family;

- prevention of negative experiences in the behaviour of students;

- physical training, promotion of a healthy lifestyle;

- provide the social protection of students and the rights of the children;

- formation of the spiritual culture of students through the national culture of the Ukrainian people.

In this study, the main interpretation of designing the educational process of the class group is as follows: previous, purposeful determination and creative modelling of programs of a class group educational activities and its further practical implementation aimed at ensuring the personal activity of adolescents.

With the help of the project, the process of organization of the educational activities of the class group becomes more predictable and algorithm-driven.

The foundation of the pedagogical design of class educational activities must consist of the following general principles of education:

1) The principle of the national orientation of students that forms in children and student's youth national consciousness, love for their native land, their people, respect for their culture; the ability to preserve their national identity be proud of their Ukrainian nationality, to participate in the development and protection of their State.

2) The principle of cultural conformity that is based on the moral and ethical experience of mankind acquired throughout history, which serves as a source of personal development of the child, a condition for the assimilation of general cultural values.

3) The principle of humanization of the educational process, which focuses on children as on the highest value, recognizes their age and individual characteristics and capabilities, encourages independence, meets the basic needs of the child (in understanding, recognition, acceptance, fair treatment); produces an individual program for children's development; stimulates a conscious attitude to their behaviour, activities, life choices.

4) The principle of subject-subject interaction encourages to avoid harsh actions, not to treat the student as a passive object of teacher's actions; participants of the educational process act as full partners in the process of communication, take into account each other's opinions, recognize the right to its difference from their own, coordinate their positions.

5) The principle of integrity - requires to organize education as a systematic pedagogical process aimed at the harmonious and versatile development of the individual, the formation of a holistic world picture; involves ensuring continuity of directions and stages of educational work at different educational levels; to cover all spheres of life of the class team group.

6) Acmeological principle that directs the educational process on high moral and spiritual achievements and potential opportunities of students; creates conditions for the achievement of students' life success, the development of their individual abilities. The areas of educational activity are concentrated in the corresponding results of firmly and organically assimilated universal and national values, life strategy, which involves a constant movement towards the implementation of new, socially significant plans.

7) The principle of life creative self-initiated activity involves the formation of a person as a creator and designer of his/her life, who is able to make independent decisions and be responsible for them, to live fully and actively under dynamic living conditions, constantly to improve themselves, adequately and flexibly respond to social changes.

8) The principle of multiculturalism, that assumes the integration of Ukrainian culture into the European and world space, the creation of the necessary prerequisites for this; forms in children an openness, tolerant attitude to ideas, values, culture, art, beliefs different from national; the ability to differentiate between common and different in different cultures, to perceive Ukrainian culture as an integral component of universal culture.

9) The principle of social conformity that determines the need for consistency of the content and methods of education of the real social situation in which the educational process is organized; provides for the formation of children's readiness for the effective solution of life problems; provides a complex of social and pedagogical assistance and protection of children; directs the pedagogical process toward the real possibilities of society, considers its most diverse factors.

10) The principle of prevention that was suiting the interests of the individual and society directs actions towards prevention of negative experiences in children and student's youth, towards help and protection, development of immunity to negative influences of the social environment. At the same time, it provides a system of measures of economic, 
legal, psychological, pedagogical, socio-medical, information and educational nature aimed at the formation of positive social attitudes, prevention of drug use, various manifestations of destructive behaviour, suicide prevention and the formation of skills of a healthy lifestyle, culture of sexual relations.

11) The principle of technologization of the educational process provides evidence-based actions of the teacher and accordingly organized actions of students, oriented towards the achievement of a specially designed system of educational objectives that are consistent with psychological mechanisms of personality development and lead to the ultimate goal of education. The educational process constructed in this way has signs of projectivity, to a certain extent, guarantees an ultimately positive outcome (Romanenko 2018, 8).

When describing the principles of education, it is necessary to emphasize that their main provisions are interrelated. The reason for this is that they help to provide a creatively thought-out holistic process of designing the class educational activities with respect to the individual characteristics of each student. The educational principles foster teaching students not only to make their own decisions but also to be answerable for them.

The main principles of educational activities design should not be ignored either. These are:

- the principle of personal priorities of the student, which is based on the preferences and choices of students;

- the principle of cooperation between teachers and students, which is to design the educational activities on the basis of subject-subject relations;

- the principle of flexibility, which outlines the creation of such designing systems that would be able to modify;

- the principle of conformity, which implies the correlation of the design with the characteristics of the age group of students.

Designing educational activities in the system of class teacher work requires a complex of various knowledge: pedagogical, psychological, philosophical, social, historical, environmental, medical, technical, information.

Consequently, from the above points, it is possible to formulate the chief purpose of designing the educational activity of the class teacher which consists in the creation of a system that corresponds to the most acceptable program of educational activity of class group for the gradual transition to a humanistic paradigm of education of teenagers and formation of the active personality which is capable to self-determination, self-organization under modern conditions.

Pedagogical thinking of a teacher is the psychological basis of design, as it enables to analyze, plan the content and forms of interaction between the teacher and students, to predict the possible consequences of pedagogical influence, where the important place occupies teacher's imagination, which makes it possible to transform reality, thereby to create a variety of types of model designs.[30]

The human factor plays a significant role in the design process. When designing the educational activities of the class group, the class teacher should be guided by knowledge of physiological characteristics, age and gender characteristics of the class members as a whole, and of each student in particular; the psychological and socio-psychological traits of students, that is, their beliefs, habits and preferences, should not be omitted either.

It can be argued that design is both a science and an art. That means the design has both a normative character (since it has certain stages, forms) and creative (since it requires strength, feelings and soul from the teacher) at the same time.

Pedagogical design, in general, contributes to the constant self-analysis of the teacher, his/her creative and professional growth, brings a positive result in working with students, contributes to the formation of general qualities necessary for the student's life self-realization.

The activity of the class teacher on the organization of joint work with the student group shows a number of features and specificity. Such work is aimed at satisfying the interests, aspirations, propensities of students, involves creativity, student's initiative in addressing the educational tasks. It is the class teacher who plays a leading role in the implementation of modern technology of educational activity on the basis of designing the development of personality, his/her cognitive interests, abilities of each student in the process of formation of the class group [29]

At the moment, the introduction of purposeful and professional management of the educational process, which involves student's education, the establishment of psychological and pedagogical diagnosis, goal-oriented planning and exercising the educational influence, objective evaluation of the real results of educational activities. The teacher's behaviour that involves decision-making and giving instructions is not effective nowadays. The teacher should be interested and together with the students be the equal participant in the educational activity.

It is important to broadly involve students in planning the process, as well as in the actual implementation of creative ideas. The type of communication within the class group, the student's progress, behaviour within the school and outside it will largely depend on the nature of the activities of students. An important element of work in this area is the involvement of schoolchildren's families, active cooperation with them, the realization of a common goal, mutual understanding. 


\section{Conclusions}

After conducting the presented study, authors came to the conclusion that more attention should be paid to the problems of individual's development and education, to building a system of student's personal development in educational institutions and organization of the educational process of the individual class group. The ideal performance of the class teacher is possible only with a clear design of class activities aimed at personal development since it contributes to the definition of a holistic educational system, the design of education of the entire class group and its individual members. It is worth mentioning that today's teachers' pay more attention to the organization of the instructional process, rather than to personality development (education). From the practice of educational institutions, it follows that a significant part of innovative processes is focused on improving the educational activities of schoolchildren. The authors believe that the priority of the modern educational institution should be personality development, which will help to form a spiritually rich person capable of self-determination and self-organization under modern conditions. To design the work plan of the class group in relation to specific educational objectives and tasks of personal development of students means to create at the level of personal development of students the most optimal system of activities, where methods and organization will be oriented towards the development of all subjects of interaction. Design is the means by which it is possible to understand the main guidelines of the activities of the subjects of the educational process, the systematization of the introduction of innovations in the educational process.

\section{REFERENCES}

[1] Oleinikova, O. (2020). Decentralization Reform: An Effective Vehicle for Modernization and Democratization in Ukraine? In Decentralization, Regional Diversity, and Conflict (pp. 311-338). Palgrave Macmillan, Cham.

[2] Lukyanchikova, K. (2020). Modern Problems of Japanese Education System. Social Science and Humanity, (1), 45-50.

[3] Aruguete, M. S., \& Mwaikinda, S. R. (2016). The efficacy of a student organization for STEM students. Journal of STEM Education: Innovations and Research, 17(3), 19-29.

[4] NE, Z., OO, S., LO, T., \& AS, M. (2019). Problems of managing interactions of general education institutions with higher education institutions. Теоретичні і прикладні проблеми психологіï, 55, 6-19 (In Russia).

[5] Dharwadkar, K. D. (2020). Mediatization In Higher Education: Towards A New Educational Paradigm? Transition from Traditional Teaching Methodology to Online Teaching, 54, 12-25.
[6] Zautorova, E. V. \& Takushevich I. A. (2016). "Pedagogical Design as the Means for Formation Value Orientations of a Person.” Penitentsiarnaya Nauka 1 (33), 77-80.

[7] Tkachova, N., \& Tkachov, A. (2018). Pedagogical conditions for the formation of personal values in the intellectually capable students of the main school (based on the study of social disciplines).

[8] Efimova, O. I., Oshchepkov, A. A., Chirkovskaya, E. G., Klepach, Y. V., \& Gridyaeva, L. N. (2017). The Experience of Studying Specific Features of Social Attitudes and Value Orientations among Normative and Deviant Teenagers. Eurasian Journal of Analytical Chemistry, 12(7b), 1549-1553.

[9] Binytska, O., \& Zdanevych, L. (2019). Training of the future specialists of pre-school education: learning the experience of the republic of Poland. Молодь і ринок, (1), 13-16. (In Russia).

[10] Merrill, M. D., Drake, L., Lacy, M. J., Pratt, J., \& ID 2 Research Group. (1996). Reclaiming instructional design. Educational Technology, 5-7.

[11] Dick, W., Carey, L., \& Carey, J. O. (2005). The systematic design of instruction.

[12] Isman, A. (2011). Instructional Design in Education: New Model. Turkish Online Journal of Educational Technology-TOJET, 10(1), 136-142.

[13] Zain, I. M., Muniandy, B., \& Hashim, W. (2016). An Integral ASIE ID Model: The 21st Century Instructional Design Model for Teachers. Universal Journal of Educational Research, 4(3), 547-554.

[14] Gagne, R. M., Wager, W. W., Golas, K. C., Keller, J. M., \& Russell, J. D. (2005). Principles of instructional design. Performance Improvement, 44(2), 44-46.

[15] Vlasenko, K., Chumak, O., Sitak, I., Lovianova, I., \& Kondratyeva, O. (2019). Training of mathematical disciplines teachers for higher educational institutions as a contemporary problem. Universal Journal of Educational Research, 7(9), 1892-1900.

[16] Vasylieva, S. (2018). The factor-criteria characteristics of a professional status formation of a teacher. 173-180. Prague-Vienna: Premier Publishing.

[17] Makarenko, A. A. (2017). Pedagogical Design as the Means for Enhancing the Efficiency of Educational Process Organization. Vestnik KGU, series "Pedagogika. Psikhologiya. Sotsiokinetika" 23(4), 13-16.

[18] Sprague, T., \& Sargsyan, C. (2014). Armenia: Changes, Challenges and Priorities. Education in Eastern Europe and Eurasia, 18, 227-235.

[19] Bakhmat, N., Maksymchuk, B., Voloshyna, O., Kuzmenko, V., Matviichuuk, T., Kovalchuk, A., ... \& Shelan, M. (2019). Designing cloud-oriented university environment in teacher training of future physical education teachers.

[20] Kirilenko, S. (2018). Formation of health-safety competences among students in the scientific pedagogical project" Intelligence of Ukraine". Наукова монографічна серія "Human health: realities and prospects", 3, 194-203 (In Russia). 
[21] Dorozhkin, E. M., Saltseva, S. V., \& Steinberg, V. E. (2016). Conceptual Model of Continuing Professional Education Based on Social-and-Academic Approach. International Journal of Environmental and Science Education, 11(16), 9348-9361.

[22] Verdes, V. (2017). The Role of Education in Personality Development. In International Multidisciplinary Scientific Conference on the Dialogue between Sciences \& Arts, Religion \& Education (Vol. 1, No. 1, pp. 51-55). Ideas Forum International Academic and Scientific Association.

[23] Patimah, S., \& Tabrani, Z. A. (2018). Counting Methodology on Educational Return Investment. Advanced Science Letters, 24(10), 7087-7089.

[24] Kirichuk, V. O. (2009). Design of Personality-Developmental Content of the Educational Process in the Computer Complex "Universal". Kyiv: Informatsiyni systemy.

[25] Sukhomlynsky, V. (1983). Selected Works in 5 Volumes (1st vol.). Kyiv: Radianska shkola.

[26] Franklin, D., Coenraad, M., Palmer, J., Eatinger, D., Zipp, A.,
Anaya, M., ... \& Weintrop, D. (2020, August). An Analysis of Use-Modify-Create Pedagogical Approach's Success in Balancing Structure and Student Agency. In Proceedings of the 2020 ACM Conference on International Computing Education Research (pp. 14-24).

[27] Kobernyk, O. (2004). Organization of Education Process Based on Psychological and Pedagogical Design. Ridna Shkola 5, 22-25 (In Russia).

[28] Elkanov, S. (1989). The Fundamentals of Future Teacher's Professional Self-Education. Moscow: Prosveshchenie

[29] Sergeeva, M. G., Bedenko, N. N., Karavanova, L. Z., Tsibizova, T. Y., Samokhin, I. S., \& Anwar, M. S. M. (2018). «Educational company»(Technology): Peculiarities of its implementation in the system of professional education. Espacios, 39(2), 24.

[30] Furman, A., \& Hirnyak, A. (2018). Psychological Technology of The Interaction Between Teacher and Students Under the Conditions of Innovative Module developmental Teaching. Міжнародні Челпанівські Психолого-Педагогічні Читання, 23, 123-135. 